\title{
Single-Walled Carbon Nanotubes/Poly Vinyl Chloride Nanocomposites and its Properties
}

\author{
${ }^{1}$ Department of Chemistry, Bacha Khan University, Charsadda, Khyber Pakhtunkhwa, Pakistan. \\ e-mail: khalidkhalil2002@yahoo.com \\ ${ }^{2}$ Department of Chemistry, University of Malakand, Chakdara, Khyber Pakhtunkhwa, Pakistan. \\ e-mail: ebraheem.chemist@gmail.com
}

\begin{abstract}
The SWNTs was purified/functionalized by acid treatment method and the F-SWNTs were used as reinforcing materials. The acid treatment introduced carboxyl $(-\mathrm{COOH})$ group to the SWNTs. The PVC and F-SWNTs/PVC films were prepared by solution casting method. The fractured surfaces of sample was analyzed through SEM and showed the dispersion of F-SWNTs in PVC. The thermal study indicated that the thermal stability of PVC is enhanced with F-SWNTs incorporation. The mechanical properties were also increased with CNTs filling. The solvent uptake study suggested that the nanocomposites resist towards solvent uptake, which is due to the hydrophobic nature of CNTs and their irregular network formation within the polymer matrix.
\end{abstract}

Keywords: Polyvinyl chloride, single walled carbon nanotubes, morphology, nanocomposite

\section{INTRODUCTION}

Since its discovery [1], CNTs is known for its unique electrical, mechanical and optical properties. A wide range of research work is done to determine the exact nature of CNTs [1-7]. CNTs are rolled graphene sheets, which can be Single-walled, double-walled or multi-walled depend on the number of rolled graphene sheets. Beside this they can be either metallic or semiconducting depending upon their chirality and diameter, thus making them ideal reinforcing materials in composite materials industry. Incorporation of very small amount of CNTs in polymeric materials can enhance their mechanical, thermal and electrical properties to greater extent. The unique properties of CNTs can also be used for engineering applications [8-11]. In CNT/polymer composites, the CNTs dispersion is the major issue encountering by the researchers and thus simple mixing of these materials is not possible with polymer matrix. This is because they are present in the form of bundles and ropes, which agglomerated to each other through Van der Waal's attractions. Beside this, higher viscosity polymeric materials, whose viscosities are relatively higher than low molar mass materials, have difficulty in penetrating the CNT bundles. To overcome these problems some physical and chemical approaches were followed. Covalent and non covalent functionalization of CNTs are the examples of chemical approaches, while sonication is the example of physical dispersion. Functionalization not only possible the even dispersion of CNTs, but also introduce a desirous functional group on it, which enable them to attached with the polymeric materials chemically $[12,13]$.

Polyvinyl chloride (PVC) is the third most widely produced plastic after polyethylene and polypropylene [14]. PVC is an important engineering polymer, which finds uses in many applications including construction, pipe, clothing, electrical cable insulation, inflatable products and many applications in which it replaces rubber [15].

Thermally PVC is relatively weaker and decomposed at $140{ }^{\circ} \mathrm{C}$ [16], thus incorporating a reinforcing materials can improve its thermal stability. Beside thermal stability, mechanical properties can also be improved as reported by Aljaafri et al [17].

In the present study, we prepared neat PVC films and its nanocomposites with F-SWNTs by solution casting method, where the F-SWNTs were used as incorporating material. After characterizing the samples through POM, TGA, UTM etc., the properties of F-SWNTs/PVC nanocomposites are compared with neat PVC. 


\section{MATERIALS AND METHODS}

\subsection{Materials}

In our study we used PVC polymer. PVC used was kindly provided by Kawsar PVC Company Peshawar, Khyber Pakhtun Khwa (KPK) Pakistan, which has average molecular weight 90,000. The CVD synthesized SWNTs were used as filler, which is purchased from Chengdu Organic Chemicals Co. Ltd., Chinese Academy of Sciences (CAS). Diameter and length of the SWNTs were 0.8-1.6 nm and 1- $2 \mathrm{~nm}$ respectively, and its purity were higher than $90 \mathrm{wt} \%$. The analytical grade chloroform was used as solvents.

\subsection{Purification/Functionalization of SWNTs}

SWNTs were purified/functionalized by the using acid treatment method [12]. Known amount of concentrated $(8 \mathrm{M}) \mathrm{HNO}_{3}$ and SWNTs were taken in distillation flask and has been refluxed for about $10 \mathrm{~h}$ at optimized temperature. The acid treated SWNTs were washed with distilled water, which removes the unwanted impurities and $\mathrm{HNO}_{3}$ traces from the final product. The F-SWNTs were dried at $105^{\circ} \mathrm{C}$ in an oven and stored for further use [12].

\subsection{Preparation of neat PVC Films}

The neat PVC film or sheet was prepared by solution casting. During this method, known amount of PVC was dissolved in $10 \mathrm{~mL}$ chloroform at room temperature. The clear thick solution was obtained, which was then cast on flat glass and finally the films or sheets were obtained after the removal of solvent (chloroform) via distilled water.

\subsection{Preparation of F-SWNTs/PVC nanocomposites}

By using weight/weight (\%) measuring unit, F-SWNTs (1 3, 7 and $10 \mathrm{wt} \%) / \mathrm{PVC}$ nanocomposites film were prepared by using the above method. To prepare $3 \mathrm{wt} \% \mathrm{~F}-\mathrm{SWNT} / \mathrm{PVC}$ nanocomposite, the known amount of F-SWNTs was added to $5 \mathrm{~mL}$ chloroform and stirred it for $15 \mathrm{~min}$. The known quantity of PVC was also dissolved into $10 \mathrm{~mL}$ chloroform and dissolved it through continuous stirring. The dispersed F-SWNTs and dissolved PVC were mixed and sonicated for $20 \mathrm{~min}$ to get a homogenous solution. The solution of FSWNTs/PVC solution was then cast on the flat glass and smooth thin films were obtained at room temperature after removal of solvent (chloroform) using distilled water. Similar procedure was adopted for 7 and $10 \mathrm{wt} \% \mathrm{~F}-\mathrm{SWNTs} / \mathrm{PVC}$ nanocomposite films.

\subsection{Characterization}

The morphological study of neat PVC and $7 \mathrm{wt} \%$ F-SWNTs/PVC was carried out with the help of SEM model JEOL, JSM-5910. These sample`s strips were fractured in liquid nitrogen and then loaded for SEM study. The fracture surfaces were gold-coated. The thermal properties of neat and F-SWNTs modified polymer nanocomposites were studied by using thermo-gravimetric analyzer (TGA) technique. The samples were studied through TG/DTA (Perkin Elmer) in nitrogen atmosphere at heating rate of $20^{\circ} \mathrm{C} / \mathrm{min}$ from room temperature to $900{ }^{\circ} \mathrm{C}$. The mechanical properties of neat polymers and their nanocomposites were analyzed by using universal testing machine (UTM), Model 100-500 KN, Iestomeric Inc. UK. The sample strips were $10-12 \mathrm{~cm}$ long, $0.5 \mathrm{~cm}$ wide and $0.01 \mathrm{~cm}$ thick.

To study the solvent uptake capacity of neat polymers and their nanocomposites, small piece of size $1 \mathrm{~cm}$ long and $0.5 \mathrm{~cm}$ wide, was cut for each solvent. This sample is then dried, weighed and immersed in vials containing about $8-10 \mathrm{~mL}$ solvents. We used distilled water, $\mathrm{HNO}_{3}(2 \mathrm{M})$ and kerosene as solvent. This study implies to know the solvent uptake of the polymers and their nanocomposites at regular interval of time. The \% solvent uptake was determined by using the following formula [22].

Solvent uptake ratio $(\%)=\{(\mathrm{W}-\mathrm{Wo}) / \mathrm{Wo}\} \times 100$

Where Wo is the weight of dry sample and $\mathrm{W}$ is the weight of wet sample in solvents. 


\section{RESULTS}

\subsection{Morphological study}

Morphological study of cryofractured neat PVC and F-SWNTs/PVC films was carried out by using SEM technique. Figure 1 shows that the neat PVC films showed smooth surface while the nanocomposite presented rough surface.

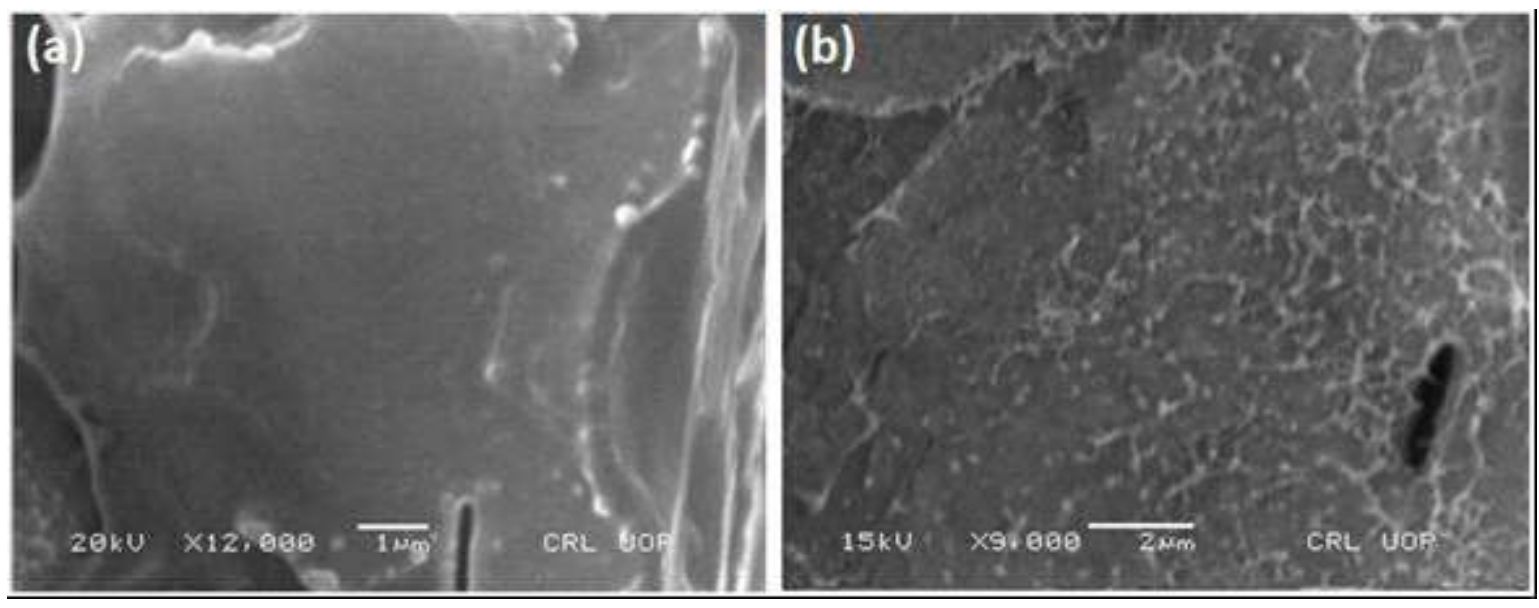

Figure 1: SEM images of (a) neat PVC and (b) F-SWNTs (7 wt \%)/PVC nanocomposite.

\subsection{Thermal study of PVC and F-SWNTs/PVC nanocomposites}

The thermal study of the neat PVC and its nanocomposites with F-SWNTs was carried out to determine the effect of F-SWNTs on the degradation temperature and variation in their thermal stabilities of PVC. The TGA thermograms of neat PVC, 3, 7 and $10 \mathrm{wt} \%$ F-SWNTs filled nanocomposites are collectively shown in the figure 2. The TGA curves of all samples show that the degradation took place at two points. The first degradation occurred at $280-380{ }^{\circ} \mathrm{C}$, while the second degradation was took place between $420-520{ }^{\circ} \mathrm{C}$.

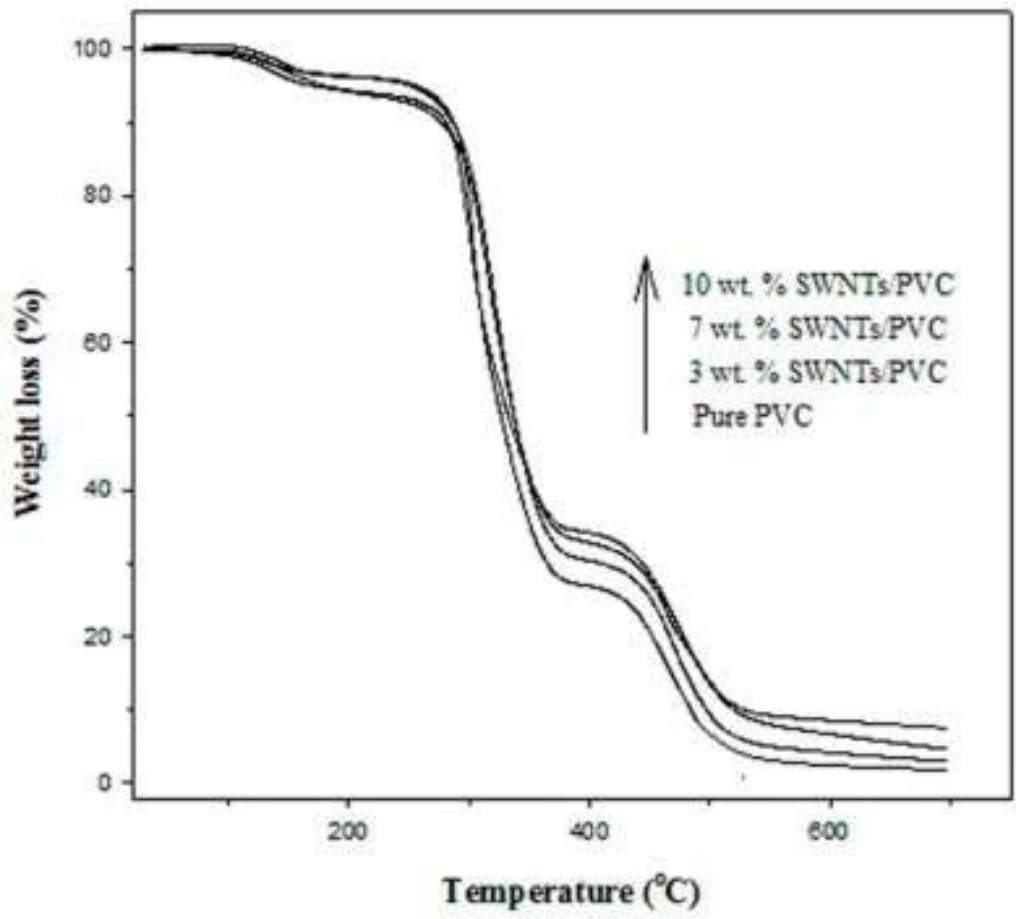

Figure 2: TGA thermograms of PVC and F-SWNTs/PVC nanocomposites 


\subsection{Mechanical properties analysis of PVC and F-SWNTs/PVC}

The mechanical properties of PVC and F-SWNTs (3, 7 and $10 \mathrm{wt} \%$ )/PVC nanocomposites are shown in table 1. The stress yield, modulus and strain yield of neat PVC was $14.45 \mathrm{~N} / \mathrm{mm}^{2}$ and $566.23 \mathrm{~N} / \mathrm{mm}^{2}$, respectively. After incorporating the F-SWNTs the values altered. The stress yield of F-SWNTs/PVC nanocomposites was increased from $32-38 \mathrm{~N} / \mathrm{mm}^{2}$. The young modulus of nanocomposites was increased in the range of 461-1394 N/mm². Similarly, the elongation at break is also jumped from 2.36 to 3.05. The elongation at break showing that the flexibility is increased in F-SWNTs/PVC nanocomposites.

Table 1: Mechanical Properties of PVC and F-SWNTs/PVC nanocomposites.

\begin{tabular}{|c|c|c|c|}
\hline SAMPLES & $\begin{array}{l}\text { STRESS YIELD } \\
\qquad\left(\mathrm{N} / \mathrm{mm}^{2}\right)\end{array}$ & $\begin{array}{c}\text { YOUNG MODU- } \\
\text { LUS } \\
\left(\mathrm{N} / \mathrm{mm}^{2}\right)\end{array}$ & $\begin{array}{c}\text { ELONGATION } \\
\text { AT THE } \\
\text { BREAK }\end{array}$ \\
\hline Neat PVC & $14.45 \pm 0.28$ & $566.23 \pm 134.49$ & $2.36 \pm 0.22$ \\
\hline 3 wt $\%$ F-SWNTs/PVC & $38.29 \pm 15.02$ & $1394.1 \pm 25.022$ & $4.22 \pm 1.44$ \\
\hline 7 wt $\%$ F-SWNTs/PVC & $34.27 \pm 7.85$ & $741.05 \pm 174.86$ & $3.37 \pm 0.43$ \\
\hline $10 \mathrm{wt} \%$ F-SWNTs/PVC & $32.29 \pm 11.72$ & $461.06 \pm 103.78$ & $3.05 \pm 1.09$ \\
\hline
\end{tabular}

\subsection{Solvent uptake study of PVC and F-SWNTs/PVC nanocomposites}

The solvent uptake study of neat PVC and F-SWNTs/PVC nanocomposites were studied in three solvents i.e. distilled water, kerosene and $\mathrm{HNO}_{3}(2 \mathrm{M})$. Tables 2-4 showed the percent solvent uptake of neat PVC and FSWNTs (3, 7 and $10 \mathrm{wt} \%) / \mathrm{PVC}$ nanocomposites. The similar method was followed as in the case of PBT and their nanocomposites. The neat PVC absorb about 200, 165, 154\% distilled water, kerosene and $\mathrm{HNO}_{3}$ solution, respectively within 48 hours. While in the case of nanocomposites, the absorption of solvents decreased as increased the quantity of F-SWNTs in PVC matrix.

Table 2: Uptake of distilled water by neat PVC and F-SWNTs/PVC nanocomposites (\%).

\begin{tabular}{c|c|c|c|c}
\hline HOURS & NEAT PVC & $\begin{array}{c}\text { 3 WT \% } \\
\text { F-SWNTS/PVC }\end{array}$ & $\begin{array}{c}\text { 7 WT \% } \\
\text { F-SWNTS/PVC }\end{array}$ & $\begin{array}{c}\text { 10 WT \% } \\
\text { F-SWNTS/PVC }\end{array}$ \\
\hline $1 / 2$ & 45.4 & 35.7 & 43.5 & 42.9 \\
\hline 1 & 90.9 & 42.9 & 82.6 & 61.9 \\
\hline 2 & 127.3 & 71.4 & 108.7 & 71.4 \\
\hline 3 & 172.7 & 107.1 & 117.4 & 128.6 \\
\hline 6 & 190.9 & 128.6 & 121.7 & 138.1 \\
\hline 12 & 209.1 & 121.4 & 130.4 & 157.1 \\
\hline 24 & 190.9 & 150.0 & 126.1 & 160.0 \\
\hline 48 & 200.0 & 142.9 & 126.1 & 158.1 \\
\hline
\end{tabular}


Table 3: Uptake of Kerosene by neat PVC and F-SWNTs/PVC nanocomposites (\%).

\begin{tabular}{c|c|c|c|c}
\hline HOURS & NEAT PVC & $\begin{array}{c}\text { 3 WT \% } \\
\text { F-SWNTS/PVC }\end{array}$ & $\begin{array}{c}\text { 7 WT \% } \\
\text { F-SWNTS/PVC }\end{array}$ & $\begin{array}{c}\text { 10 WT \% } \\
\text { F-SWNTS/PVC }\end{array}$ \\
\hline $1 / 2$ & 37.5 & 29.412 & 30.5 & 35.77 \\
\hline 1 & 75 & 64.706 & 56.06 & 57.5 \\
\hline 2 & 125 & 131.76 & 88.55 & 112.5 \\
\hline 3 & 137.5 & 138.53 & 140.02 & 129 \\
\hline 6 & 150 & 135.29 & 122.5 & 146 \\
\hline 12 & 137.5 & 142.53 & 128.05 & 137.5 \\
\hline 24 & 162.5 & 147.06 & 135.45 & 154.5 \\
\hline 48 & 165 & 149.41 & 135.45 & 152.5 \\
\hline
\end{tabular}

Table 4: Uptake of $\mathrm{HNO}_{3}$ solution by neat PVC and F-SWNTs/PVC nanocomposites (\%).

\begin{tabular}{c|c|c|c|c}
\hline HOURS & NEAT PVC & $\begin{array}{c}\text { 3 WT \% } \\
\text { F-SWNTS/PVC }\end{array}$ & $\begin{array}{c}\text { 7 WT \% } \\
\text { F-SWNTS/PVC }\end{array}$ & $\begin{array}{c}\text { 10 WT \% } \\
\text { F-SWNTS/PVC }\end{array}$ \\
\hline $1 / 2$ & 45.45 & 53.85 & 66.67 & 36.36 \\
\hline 1 & 100 & 107.7 & 91.67 & 54.55 \\
\hline 2 & 127.3 & 169.2 & 83.33 & 63.64 \\
\hline 3 & 200 & 146.2 & 108.3 & 118.2 \\
\hline 6 & 181.8 & 161.5 & 116.7 & 127.3 \\
\hline 12 & 209.1 & 184.6 & 116.7 & 145.5 \\
\hline 24 & 245.5 & 200 & 133.3 & 154.5 \\
\hline 48 & 254.5 & 207.7 & 158.3 & 190.9 \\
\hline
\end{tabular}

\section{DISCUSSION}

The morphological study presented that the F-SWNTs is will embedded within the PVC matrix (Figure 1). It is reported that if CNTs dispersed well in the concerned polymer matrix then it significantly improved the properties like mechanical, thermal, electrical etc. of that polymer [12, 18].

The TG thermograms presented two stages degradation (Figure 2). The first stage degradation is possibly due to the dehydrochlorination during the thermal degradation of PVC [19]. The TGA curves clearly presented that the thermal stabilities of F-SWNTs/PVC nanocomposites was improved about $20-25{ }^{\circ} \mathrm{C}$ as compared to the neat PVC samples.

The mechanical properties of PVC and F-SWNTs (3, 7 and $10 \mathrm{wt} \%$ )/PVC nanocomposites are shown in table 1. It was found that the mechanical properties of the nanocomposites were higher than the neat PVC. The result also indicated that the mechanical properties of F-SWNTs/PVC nanocomposites decreased when the amount of loaded F-SWNTs increased, which is might be due to agglomeration of F-SWNTs in PVC matrix using high nanotubes quantity. The results also presented that in case of $3 \mathrm{wt} \% \mathrm{~F}-\mathrm{SWNTs} / \mathrm{PVC}$ all the values are enhanced, which means that the F-SWNTs are effectively dispersed upto 3 wt \% in PVC matrix.

The solvent uptake study (tables 2-4) illustrated that the initially more solvent is absorbed by the samples and thus sudden increase in the solvent uptake is observed but this increase is paused after some readings as equilibrium reached. After comparing the results, it is cleared that the introduction of F-SWNTs reduced the solvent uptake capacity of the polymer appreciably. As compared to neat PVC, the \% solvent uptake is low for nanocomposite samples, especially in case of $3 \mathrm{wt} \% \mathrm{~F}-\mathrm{SWNTs} / \mathrm{PVC}$ nanocomposite [20]. 
The reason for lower solvent uptake by the PVC nanocomposites is the interaction of F-SWNTs and PVC, which bound the PVC from solvent uptake. However $10 \mathrm{wt} \%$ F-SWNTs/PVC nanocomposites showed relatively high solvent uptake then other nanocomposites in all solvents, which might be due to the high concentration of F-SWNTs, which cause agglomeration. Agglomeration of SWNTs causes more porosity and enhanced solvent uptake, as reported by Stephen et al [21]. The solvent show similar uptake pattern as was in the case of PBT nanocomposites i.e. water and $\mathrm{HNO}_{3}$ showed appreciable solvent uptake then kerosene. The high molecular mass of kerosene molecules might be the cause of lowering of solvent uptake.

\section{CONCLUSIONS}

In this study, neat PVC and F-SWNTs/PVC nanocomposites were prepared by solution casting method. The main objective of the work is to study the effect of F-SWNTs on the properties of PVC polymer. The SEM images clearly showed that the F-SWNTs are fully dispersed in the polymer matrix of PVC. The thermal properties of the polymer were improved significantly. It was also found that the addition of F-SWNTs greatly enhanced the mechanical properties of the target polymers. The solvent uptake study of samples showed that the \% solvent uptake of nanocomposites is decreased due to hydrophobic nature of CNTs and its interaction with the polymer.

\section{ACKNOWLEDGMENTS}

The work was partially supported by the Higher Education Commission of Pakistan (HEC) and Kawsar PVC Company Peshawar for providing PVC polymer.

\section{BIBLIOGRAPHY}

[1] IIJIMA, S., “Helical microtubules of graphitic carbon”, Nature, v. 354, pp. 56-58, 1991.

[2] RASHAD, A M., "Effect of carbon nanotubes (CNTs) on the properties of traditional cementitious materials", Construction and Building Materials, v. 153, pp. 81-101, 2017.

[3] LAU, K. T., HUI, D. "The revolutionary creation of new advanced materials-carbon nanotube composites”, Composites Part B: Engineering, v. 33, pp. 263-277, 2002.

[4] DALTON, B., COLlinS, S., MUNOZ, E., et al., "Super-tough carbon-nanotube fibres-These extraordinary composite fibres can be woven into electronic textiles”, Nature, v. 423, pp. 703-706, 2003.

[5] ESHKALAK, S. K., CHINNAPPAN, A., JAYATHILAKA, W.A.D.M., et al., "A review on inkjet printing of CNT composites for smart applications", Applied Materials Today, v. 9, pp. 372-386, 2017.

[6] IIJIMA, S., ICHIHASHI, T., “Single-shell carbon nanotubes of 1-nm diameter”, Nature, v. 363, pp. 603$605,1993$.

[7] ENDO, M., TAKEUCHI, K., IGARASHI, S., et al., "The production and structure of pyrolytic carbon nanotubes (PCNTs)", Journal of Physics and Chemistry of Solids, v. 54, pp. 1841-1846, 1993.

[8] CHA, J., JUN, G. H., PARK, J.K., et al., "Improvement of modulus, strength and fracture toughness of CNT/Epoxy nanocomposites through the functionalization of carbon nanotubes", Composites Part B: Engineering, v. 129, pp. 169-179, 2017.

[9] HELlAND, A., WICK, P., KOEHLER, A., SCHMID, K., et al., "Reviewing the environmental and human health knowledge base of carbon nanotubes," Environmental Health Perspectives, v. 115, pp. 11251131, 2007.

[10] BAUGHMAN, R. H., ZAKHIDOV, A. A., HEER, W. A. D., "Carbon nanotubes the route toward applications", Science, v. 297, pp. 787-792, 2002.

[11] CAO, A. Y., ZHU, H. W., ZHANG, X. F., et al., "Hydrogen storage of dense aligned carbon nanotube", Chemical Physics Letters, v. 342, pp. 510-514, 2001.

[12] SAEED, K., "Review on the properties, dispersion and toxicology of carbon nanotubes", Journal of the Chemical Society of Pakistan, v. 32, pp. 561-567, 2010.

[13] LIU, C. -X., CHOI, J. -W., "Improved Dispersion of Carbon Nanotubes in Polymers at High Concentrations", Nanomaterials, v. 2, pp. 329-347, 2012.

[14] ALlSOPP, M. W., VIANELlO, G. "Poly(Vinyl Chloride),” in Ullmann's Encyclopedia of Industrial Chemistry, 2012, Wiley-VCH, Weinheim. 
[15] TITOW, W. V., (31 December 1984). PVC technology. Springer. pp. 6. ISBN 978-0-85334-249-6. Retrieved 6 October 2011.

[16] Properties of PVC (polyvinyl chloride). JT-EXTRUDERMACHINE.COM

[17] ALJAAFARI, A. A., IBRAHIM, S. S., EL-BROLOSSY, T. A., "Thermophysical and electrical characterization of PVC-SWNT nanocomposites", Composites Part A: Applied Science and Manufacturing, v. 42, pp. 394-399, 2011.

[18] SAEED, K., PARK, S. Y., "Multi-walled carbon nanotubes/Poly (butylene terephthalate) Nanofibres: Morphological, Mechanical and Thermal Properties", Iranian Polymer Journal, v. 20, pp. 795-802, 2011.

[19] CHAKRABARTI, R., DAS, M., CHAKRABORTY, D., "Physical, mechanical, and thermal properties of PVC/PMMA blends in relation to their morphologies", Journal of Applied Polymer Science, v. 93, pp. 2721-2730, 2004.

[20] MISHRA, J. K., KIM, G. H., KIM, I., et al., "A New Thermoplastic Vulcanizate (TPV)/Organoclay Nanocomposite: Preparation, Characterization, and Properties", Journal of Polymer Science Part B: Polymer Physics, v. 42, pp. 2900-2908, 2004.

[21] STEPHEN, R., VARGHESE, S., JOSEPH, K., et al., "Diffusion and transport through nanocomposites of natural rubber (NR), carboxylated styrene butadiene rubber (XSBR) and their blends," Journal of Membrane Science, v. 282, pp. 162-170, 2006.

[22] SAEED, K., PARK, S. Y., ALI, N., "Characterization of Poly(butylene Terephthalate) Electrspun Nanofibres Containing Titanium Oxide”, Iranian Polymer Journal, v. 18, pp. 671-677, 2009.

ORCID

Khalid Saeed

https://orcid.org/0000-0002-0240-3861

Ibrahim Khan

https://orcid.org/0000-0003-2893-1467 